
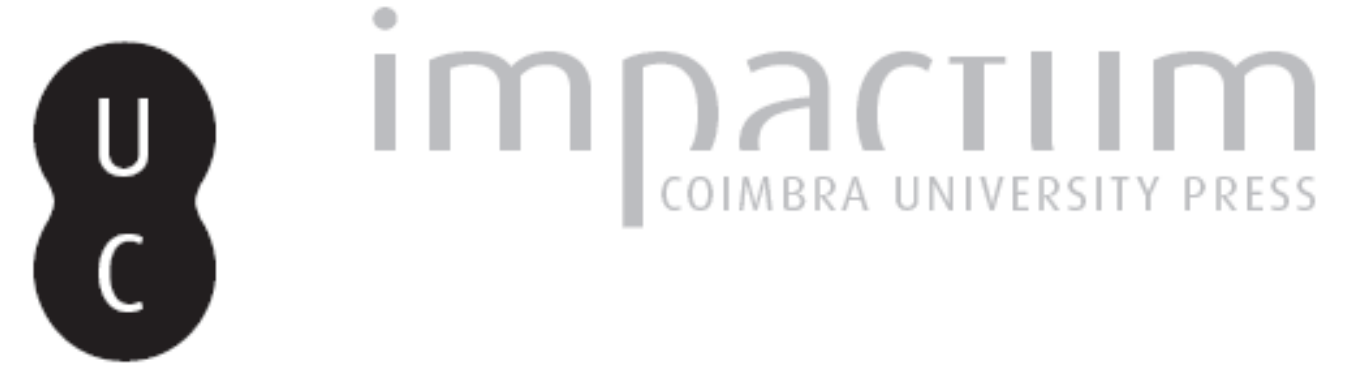

\title{
Legislación de Costas y planificación urbanística María del Carmen Nuñez Lozano, Cuadernos Universitarios de Derecho Administrativo
}

Autor(es): $\quad$ Oliveira, Fernanda Paula

\section{Publicado por: CEDOUA}

URL persistente:

URI:http://hdl.handle.net/10316.2/8852

DOI:

http://dx.doi.org/10.14195/2182-2387_23_6

Accessed : $\quad$ 26-Apr-2023 12:21:11

A navegação consulta e descarregamento dos títulos inseridos nas Bibliotecas Digitais UC Digitalis, UC Pombalina e UC Impactum, pressupõem a aceitação plena e sem reservas dos Termos e Condições de Uso destas Bibliotecas Digitais, disponíveis em https://digitalis.uc.pt/pt-pt/termos.

Conforme exposto nos referidos Termos e Condições de Uso, o descarregamento de títulos de acesso restrito requer uma licença válida de autorização devendo o utilizador aceder ao(s) documento(s) a partir de um endereço de IP da instituição detentora da supramencionada licença.

Ao utilizador é apenas permitido o descarregamento para uso pessoal, pelo que o emprego do(s) título(s) descarregado(s) para outro fim, designadamente comercial, carece de autorização do respetivo autor ou editor da obra.

Na medida em que todas as obras da UC Digitalis se encontram protegidas pelo Código do Direito de Autor e Direitos Conexos e demais legislação aplicável, toda a cópia, parcial ou total, deste documento, nos casos em que é legalmente admitida, deverá conter ou fazer-se acompanhar por este aviso.

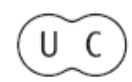


Doutrina

N.․․ 23 _Ano XII_1. 09

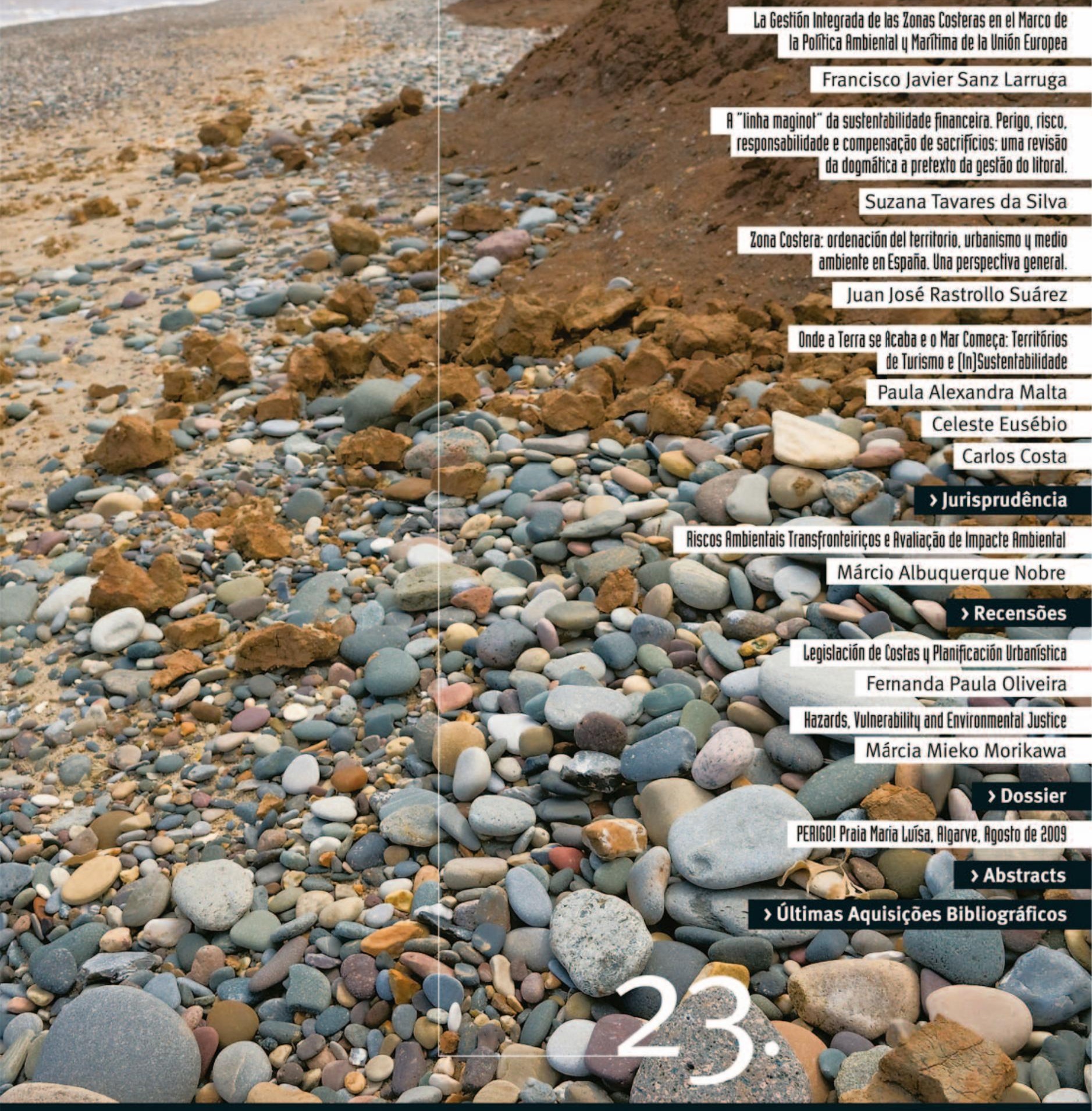

Revista do Centro de Estudos de Direito do Ordenamento, do Urbanismo e do Ambiente Urbanism, Territorial Order and Environment Studies Center Law Review 


\section{Legislación de Costas y Planificación Urbanística María del Carmen Nuñez Lozano, Cuadernos Universitarios de Derecho Administrativo, Sevilha, 2009 (266 páginas)}

\section{0 objecto de estudo}

0 livro aqui em recensão, com Prólogo de Àngel Menéndez Rexach, tem como objecto de análise a "Lei Costeira" Espanhola de 1988: Lei 22/1988, de 28 de Julho que regula a protecção, utilização e polícia do domínio público marítimo-terrestre, cuja regulamentação foi aprovada pelo Real Decreto n. ${ }^{1471 / 1989}$, de 1 de Dezembro.

Como decorre da respectiva exposição de motivos, esta lei teve como razão imediata de ser a progressiva destruição e privatização do litoral e a necessidade de estabelecer uma solução clara e inequívoca conforme com a natureza destes bens, com vista à defesa de seu equilíbrio; à protecção e conservação dos seus valores e virtualidades naturais e culturais; ao aproveitamento racional dos seus recursos; à garantia do seu uso e desfrute por todos (com excepções apenas justificadas no interesse colectivo e estritamente limitadas no tempo e no espaço) e à adopção das adequadas medidas de recuperação.

Trata-se de uma das mais importantes leis sectoriais do país vizinho cuja aplicação prática suscitou inúmeras dificuldades e problemas que justificam a ampla produção doutrinária e jurisprudencial de que a obra dá nota.

\section{A sistemática da obra}

O livro centra-se no Capítulo II da Lei Costeira - limitações ao direito de propriedade sobre os terrenos contíguos à ribeira de mar por razões de protecção do domínio público marítimoterrestre -, embora analise também o seu Titulo III, sobre a utilização deste domínio cujo regime condiciona também o ordenamento urbanístico, ao estabelecer limites e critérios de utilização do solo no espaço dominial.

Concretamente, para além da introdução, onde se expõem alguns dos problemas que se colocam às zonas costeiras, em especial por força da forte pressão urbana que sobre a mesma ocorre - aqui se refere à desregrada ocupação urbanística do litoral, considerada a sua ameaça mais grave, bem como aos contraditórios interesses (designadamente ambientais e económicos) em tensão que sobre ela se fazem sentir e à peculiaridade do urbanismo do litoral -, a obra contém cinco Capítulos (Capítulo II a VI), onde se analisam as determinações, em sentido amplo, que a legislação costeira impõe ao planeamento urbanístico incidente sobre espaços do litoral, identificando os critérios e os conteúdos (designadamente em termos de usos permitidos e proibidos) que vinculam os diferentes instrumentos de planeamento. Aqui se trata, concretamente, dos critérios e conteúdos impostos à planificação urbanística decorrentes da existência de uma servidão de proteç̧ão (Capítulo II), de uma servidão de trânsito (Capítulo III), de servidões de acesso ao mar (Capítulo III) bem como os limites à planificação urbanística impostos nas zonas de influência da "ribeira del mar" (Capítulo IV) e do regime próprio desta (Capítulo VI). 


\section{RerCEDőUA}

Este estudo é completado com a análise da forma como o litoral merece consideração na Lei de Ordenação Urbanística da Andaluzia de 2002 (Capítulo VII) e pela referência às garantias do respeito pelas determinações da Lei Costeira por parte da planificação urbanística (Capítulo VIII), que são, no seu essencial, os pareceres da Administração costeira estadual no procedimento de elaboração dos instrumentos de planeamento urbanístico - que correspondem a técnicas de cooperação e de coordenação entre as Administrações intervenientes e se apresentam como instrumentos indispensáveis para a articulação de competências concorrentes sobre o mesmo território -, e o regime de impugnação previsto na Lei Costeira (de menor relevo por este regime ter, entretanto, sido absorvido pela legislação do contencioso de 1998).

Tudo isto depois de uma apresentação geral da regulamentação substantiva da Lei Costeira e do respectivo Regulamento (Capítulo I).

\section{0 realce de algumas questões}

Sem entrar no pormenor de cada um dos Capítulos desta obra - os quais revelam o conteúdo específico desta lei e as várias dúvidas que a respectiva aplicação tem colocado na praxis (exposta na ampla jurisprudência citada e explanada) -, enumeram-se aqui, apenas, dada a sua importância, a questão da classificação dos solos das áreas abrangidas pela regulamentação da Lei Costeira; a questão da indemnizabilidade das restrições decorrentes de algumas das servidões dela constantes e o complexo regime transitório que a mesma integra.

0 relevo da questão da classificação dos solos decorre do facto de, por motivos de ordem constitucional de distribuição de competências, a Lei Costeira não poder impor uma determinada classificação das áreas por ela abrangidas, não decorrendo, por isso, dela, a obrigação de tais solos serem classificados como não urbanizáveis, pese embora esta fosse a categoria de uso do solo mais adequada, tendo em conta os usos que para ela são permitidos. Assim, e como afirma a autora a certa altura (p. 219) "pode concluir-se que não existe uma incompatibilidade entre a natureza física da ribeira do mar e a classificação dos terrenos como urbanos, sem prejuizo de os usos possiveis serem apenas aqueles que a Lei Costeira consente. Esem prejuizo também de insistirmos que a classificação que mais convém à ribeira do mar é a de solo não urbanizável, o que não impede que determinadas extensões da mesma se encontrem dotadas de certos serviços característicos do solo urbano, normalmente no seu limite interior (...) devendo, tais solos, por isso, ser classificados de urbanos" (tradução livre).

No que concerne ao regime transitório, conclui-se, da leitura desta obra, ter o mesmo um carácter altamente complexo (o qual depende, entre outros critérios, do tipo de instrumento de planeamento vigente à data da entrada em vigor desta lei e da concreta classificação dos solos dele constantes). Cfr., a título de exemplo, as considerações constantes das pp. 93 a 146 desta obra, de onde decorre que o regime aplicável varia consoante à data da entrada em vigor da Lei o solo estivesse classificado como urbano, como não urbanizável, como urbanizável não programado ou como urbanizável programado ou apto a programar (e neste caso, dependendo se à data da entrada em vigor da referida Lei estivesse já, ou não, definitivamente aprovado plano parcial; estando este aprovado, consoante o mesmo estivesse ou já, ou não, executado e, em caso negativo, consoante a não execução se devesse ou não a causas imputáveis à Administração).

Em face deste regime transitório, considera a autora que a interpretação e aplicação das normas transitórias acabaram por perpetuar e, mesmo, incentivar a construção no litoral, de onde conclui que esta lei "mas que llegar tarde, arribó parcialmente desarmada" (p. 37).

A este propósito afirma Menéndez Rexach, no prólogo, que para o bem ou para o mal, o legislador espanhol legisla quase sempre a "custo zero", não sendo a Lei Costeira uma excepção a esta tendência. Para este autor, o critério básico das normas transitórias deste diploma legal foi o de "aplicar las previsiones legales com toda la intensidad posible, pero evitando la necesidad de indemnizar" (p. 18). 


\section{$\operatorname{RerCED\varrho ̋UA~}$ \\ > Recensão}

\section{Considerações conclusivas}

Numa súmula muito geral do que retiramos da leitura desta obra, formulamos aqui dois tipos de considerações.

A primeira prende-se com a necessidade de este tipo de legislação (vocacionada para áreas sensíveis, como é o litoral), mais do que ser assumida pelo planificador urbanístico como um limite à discricionariedade de que dispõe na conformação do território (e, por isso, como uma vinculação negativa no sentido de que as suas prescrições devem ser respeitadas nos planos urbanísticos), deve antes ser aproveitada como título justificativo para opções planificadoras de promoção de uma correcta e sustentável utilização destas áreas (isto é, como directivas positivas nesse sentido).

A segunda diz respeito ao facto de em Espanha, como em Portugal, a zona costeira corresponder a uma área de confluência não apenas de distintos (e quantas vezes, contraditórios) interesses públicos e privados, mas também de intervenção e decisão de distintas entidades, portadoras (curadoras) de interesses públicos diferenciados. Por este motivo, a cooperação interadministrativa se apresenta como imprescindível a uma correcta (diríamos, integrada) gestão do litoral, na medida em que nenhuma daquelas entidades está em condições de, por si só, assegurar a efectividade de gestão destas áreas.

De acordo com a "Comunicação da Comissão ao Conselho e ao Parlamento Europeus sobre a Gestão Integrada das Zonas Costeiras: uma estratégia para a Europa", de 2000, a gestão integrada das zonas costeiras é um processo que pressupõe um novo modo de gestão que requer a participação de todos os segmentos da sociedade civil e a colaboração de todas as partes interessadas em elaborar e aplicar um modelo de desenvolvimento que sirva o interesse de todos.

Ora, a gestão integrada das zonas costeiras deve implicar, não a concentração de todas as competências concorrentes referentes ao litoral numa só entidade (o que seria dificilmente conciliável com a organização territorial do Estado definida constitucionalmente, em que a cada entidade territorial devem ser reconhecidas as atribuições que melhor se adeqúem à esfera de interesses que representam), mas antes a cooperação e coordenação entre aquelas entidades (e as suas atribuições).

É esta cultura de cooperação e de coordenação (em vez de uma visão exclusivista e fragmentada das competências), que terá de ser reforçada para se alcançar aquele objectivo.

Estamos, assim, com Àngel Méndez Rexach que afirma, no prólogo da obra aqui em recensão, que "a defesa do litoral, como património colectivo, é tarefa de todos, poderes públicos e cidadãos. Cooperação, coordenação e participação são, assim, os três pilares da gestão integrada do litoral".

Fernanda Paula Oliveira
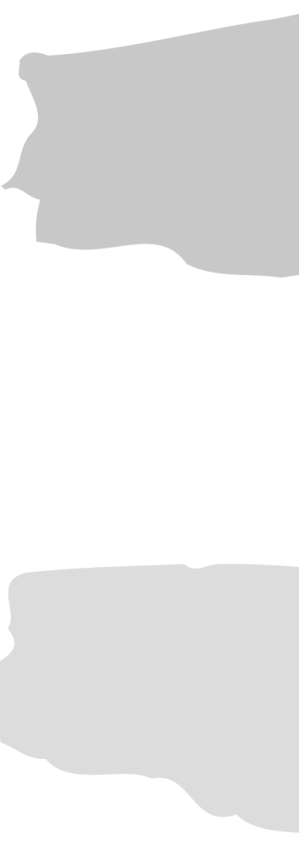